\title{
Comprehensive analysis of the IncRNA-associated competing endogenous RNA network in breast cancer
}

\author{
JING-JING WANG ${ }^{1 *}$, YUE-QING HUANG ${ }^{2 *}$, WEI SONG ${ }^{3 *}$, YI-FAN LI ${ }^{4}$, \\ HAN WANG ${ }^{5}$, WEN-JIE WANG ${ }^{6}$ and MIN HUANG ${ }^{2}$
}

\begin{abstract}
${ }^{1}$ Department of Oncology, Taizhou Hospital of Traditional Chinese Medicine, Taizhou, Jiangsu 225300; Departments of ${ }^{2}$ General Practice and ${ }^{3}$ Intervention and Vascular Surgery, The Affiliated Suzhou Hospital of Nanjing Medical University, Suzhou, Jiangsu 215001; ${ }^{4}$ Department of Oncology, Binzhou People's Hospital, Binzhou, Shandong 256600; ${ }^{5}$ Department of Oncology, Jining Cancer Hospital, Jining, Shandong 272000; ${ }^{6}$ Department of Radio-Oncology, The Affiliated Suzhou Hospital of Nanjing Medical University, Suzhou, Jiangsu 215001, P.R. China
\end{abstract}

Received December 29, 2018; Accepted September 19, 2019

DOI: $10.3892 /$ or.2019.7374

\begin{abstract}
Long noncoding RNAs (lncRNAs) have been confirmed to be potential prognostic markers in a variety of cancers and to interact with microRNAs (miRNAs) as competing endogenous RNAs (ceRNAs) to regulate target gene expression. However, the role of IncRNA-mediated ceRNAs in breast cancer $(\mathrm{BC})$ remains unclear. In the present study, a ceRNA network was generated to explore their role in BC. The expression profiles of mRNAs, miRNAs and lncRNAs in 1,109 BC tissues and 113 normal breast tissues were obtained from The Cancer Genome Atlas database (TCGA). A total of 3,198 differentially expressed (DE) mRNAs, 150 differentially DEmiRNAs and 1,043 DElncRNAs were identified between $\mathrm{BC}$ and normal tissues. A lncRNA-miRNA-mRNA network associated with $\mathrm{BC}$ was successfully constructed based on the combined data obtained from RNA databases, and comprised 97 lncRNA nodes, 24 miRNA nodes and 74 mRNA nodes. The biological functions of the 74 DEmRNAs were further investigated by Gene Ontology (GO) and Kyoto Encyclopedia of Genes and Genomes (KEGG) pathway analysis. The results demonstrated that the DEmRNAs were significantly enriched in two GO biological process categories; the main biological process enriched term was 'positive regulation
\end{abstract}

Correspondence to: Dr Min Huang, Department of General Practice, The Affiliated Suzhou Hospital of Nanjing Medical University, 26 Daoqian Street, Suzhou, Jiangsu 215001, P.R. China E-mail: cxy442941186@163.com

Dr Wen-Jie Wang, Department of Radio-Oncology, The Affiliated Suzhou Hospital of Nanjing Medical University, 26 Daoqian Street, Suzhou, Jiangsu 215001, P.R. China

E-mail: doctor.wjwang@gmail.com

*Contributed equally

Key words: breast cancer, long non-coding RNA, competing endogenous RNA network, overall survival of GTPase activity'. By KEGG analysis, four key enriched pathways were obtained, including the 'MAPK signaling pathway', the 'Ras signaling pathway', 'prostate cancer', and the 'FoxO signaling pathway'. Kaplan-Meier survival analysis revealed that six DElncRNAs (INC AC112721.1, LINC00536, MIR7-3HG, ADAMTS9-AS1, AL356479.1 and LINC00466), nine DEmRNAs (KPNA2, RACGAP1, SHCBP1, ZNF367, NTRK2, ORS1, PTGS2, RASGRP1 and SFRP1) and two DEmiRNAs (hsa-miR-301b and hsa-miR-204) had significant effects on overall survival in BC. The present results demonstrated the aberrant expression of INC AC112721.1, AL356479.1, LINC00466 and MIR7-3HG in BC, indicating their potential prognostic role in patients with $\mathrm{BC}$.

\section{Introduction}

Breast cancer (BC) is the most common type of cancer among females and accounts for $\sim 16 \%$ of all cancers (1). BC is a heterogeneous malignant tumor derived from breast tissue and is the main cause of cancer-associated mortality in females worldwide $(2,3)$. Surgery and adjuvant therapy can effectively improve the prognosis of patients with BC; however, metastasis and recurrence can still occur $(4,5)$. The development of $\mathrm{BC}$ is a complex process, involving genetic and epigenetic changes (6). Due to the heterogeneity of BC, clinical outcomes vary. The predictive value of current diagnostic and prognostic factors for BC is limited. Thus, it is essential to identify effective diagnostic markers, therapeutic targets and prognostic factors. Recently, competing endogenous RNAs (ceRNAs) have been investigated in the process of tumorigenesis and cancer development $(7,8)$. Salmena et al $(7)$ proposed the ceRNA hypothesis in 2011 , in which a complex post-transcriptional control network involving all types of RNA transcripts suppresses the functions of microRNAs (miRNAs/miRs) via miRNA response elements.

Long non-coding RNAs (lncRNAs) are a class of noncoding RNAs with a length $>200$ nucleotides (9); a lncRNA may function as an oncogene or a tumor suppressor to regulate the expression of target genes at various levels $(10,11)$. Increasing evidence has demonstrated that lncRNAs serve 
an important role in several cellular processes $(12,13)$. The predictive value of lncRNAs has been reported in multiple types of cancer, including lung cancer (14), gallbladder cancer (15), ovarian cancer (16), glioblastoma (17), gastric cancer (18), pancreatic cancer (19) and colorectal cancer (20). Abnormal expression of certain lncRNAs has been observed in $\mathrm{BC}$, and it has been associated with diagnosis and prognosis of the disease (21). However, due to the limited number of tissue samples employed, the results of these studies in BC are inconsistent $(22,23)$.

In the present study, the expression profiles of mRNAs, miRNAs and lncRNAs in BC and non-cancer tissues were obtained from The Cancer Genome Atlas (TCGA). An lncRNA-ceRNA network associated with BC was successfully constructed. In addition, functional enrichment analysis was conducted to investigate the potential mechanism. Survival analysis was also performed for the differentially expressed genes (DEGs) and their association with BC prognosis was explored. Differentially expressed RNAs (DERNAs) in the ceRNA network were analyzed to further investigate the development and prognosis of $\mathrm{BC}$.

\section{Materials and methods}

Data acquisition and processing. RNA sequencing (RNA-Seq) and the corresponding clinical data of BC patients were obtained from the TCGA data portal (https://tcga-data.nci.nih. gov/tcga/). The lncRNA, mRNA and miRNA sequence data were derived from Illumina HiSeq RNA Seq and Illumina HiSeq miRNA Seq platforms. A total of 1,109 BC tissues and 113 normal breast tissues were included in the present study. The inclusion criteria were as follows: i) Gender was female; and ii) histopathology was confirmed as ductal or lobular disease. The exclusion criteria were as follows: i) Gender was male; and ii 2) histopathology was not confirmed as ductal and lobular disease. The present study was conducted in accordance with the publication guidelines provided by the TCGA (http://cancergenome.nih.gov/publications/publicationguidelines). Therefore, further approval from an ethics committee was not required.

Identification of DERNAs. Differentially expressed lncRNA (DElncRNA) and differentially expressed mRNA (DEmRNA) were defined and encoded based on the annotations from the Ensembl database (http://www.ensembl.org/index.html). To further analyze the data, the edgeR package in the $\mathrm{R}$ language 3.53 was used (http://bioconductor.org/packages/edgeR/), and the DElncRNA, DEmRNA and differentially expressed miRNA (DEmiRNA) were identified. A llog2 fold change (FC) $\mid>1.5$ and false discovery rate (FDR) adjusted to a P-value $<0.01$ were set as the thresholds. Volcano plots and heatmaps of the DERNAs were produced by using the gplots and heatmap packages in the $\mathrm{R}$ platform, respectively.

Construction of the ceRNA network. The miRcode (http://www.mircode.org/) database (24) was used to predict lncRNA-miRNA interactions, and the StarBase v2.0 (25) database (http://starbase.sysu.edu.cn/) was used to decode the miRNA sequences. In addition, miRNA-targeted mRNAs were retrieved from the miRDB (26), miRTarBase (27), and
TargetScan (28) databases. Only the mRNAs recognized by all three databases were considered as candidate mRNAs and were then intersected with the DEmRNAs to determine the DEmRNAs that were targeted by the DEmiRNAs. Based on the DEmiRNA-DElncRNA and DEmiRNA-DEmRNA interactions, a coexpression network of DEGs was constructed, which was visualized using Cytoscape 3.6.1 (29). In addition, the cytoHubba plugin was used to evaluate the top 15 genes in the network based on closeness.

Functional enrichment analysis. To understand the underlying biological mechanisms of the DEmRNAs in the ceRNA crosstalk network, Gene Ontology (GO) annotation and Kyoto Encyclopedia of Genes and Genomes (KEGG) pathway analyses were conducted using the DAVID (database for annotation, visualization, and integrated discovery; https://avid. ncifcrf.gov/) online tool (30) and cluster profiler, which is an $\mathrm{R}$ package for functional classification and enrichment of gene clusters using hypergeometric distribution. The GO plot package of $\mathrm{R}$ software was used to display the results of the GO and KEGG analyses. GO and KEGG enrichment analyses were based on the threshold of $\mathrm{P}<0.05$.

Survival analysis. The high expression and low expression groups were classified according to the median. Survival analysis was performed for the DERNAs in the ceRNA network using the 'survival' package in $\mathrm{R}$ to assess their prognostic value in patients with BC. Survival curves were generated using the Kaplan-Meier method, and the log-rank test was used to compare the differences between the groups. $\mathrm{P}<0.05$ was considered as the threshold for significance in all analyses.

\section{Results}

DEmRNAs, DElncRNAs and DEmiRNAs in BC. Significant DEGs were identified in $1,109 \mathrm{BC}$ and 113 adjacent non-cancer breast tissues using the 'edge R' package in $\mathrm{R}$ software. A total of 3,198 DEmRNAs (1,996 upregulated and 1,202 downregulated), 1,043 DElncRNAs (814 upregulated and 229 downregulated), and 150 DEmiRNAs (114 upregulated and 36 downregulated) were identified with thresholds of $\mid \log _{2}$ fold change $(\mathrm{FC}) \mid>1.5$ and adjusted $\mathrm{P}<0.01$. The distribution of DEGs based on the two parameters, -log false discovery rate and $\log \mathrm{FC}$, was presented as a volcano plot (Fig. 1A). The heatmap demonstrated the expression data of all DEGs (Fig. 1B).

Construction of the ceRNA network. To investigate how lncRNAs mediate mRNA expression by integrating with miRNAs in BC, a lncRNA-miRNA-mRNA (ceRNA) network was generated and visualized using Cytoscape v3.6.1. A total of 405 pairs of interacting lncRNAs and miRNAs were identified using the Perl program 5.30.0 (http://www.perl.org/) (31), based on the 1,043 DElncRNAs. Based on 24 miRNAs, target mRNAs were identified using the miRTarBase, miRDB and TargetScan databases. Target genes that were included in all three datasets were selected. Finally, there were 74 DEmRNAs in the ceRNA network (Fig. 2). In total, 97 lncRNA nodes, 24 miRNA nodes and 74 mRNA nodes were identified as 
A

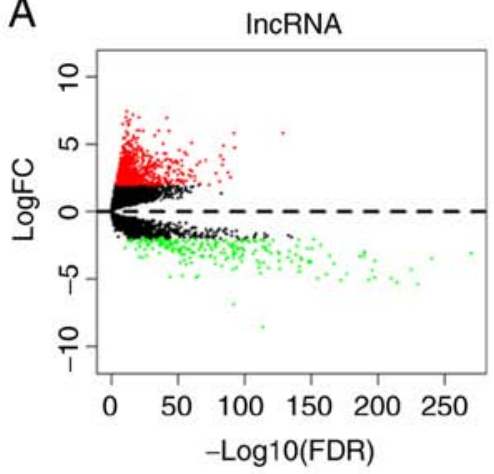

B

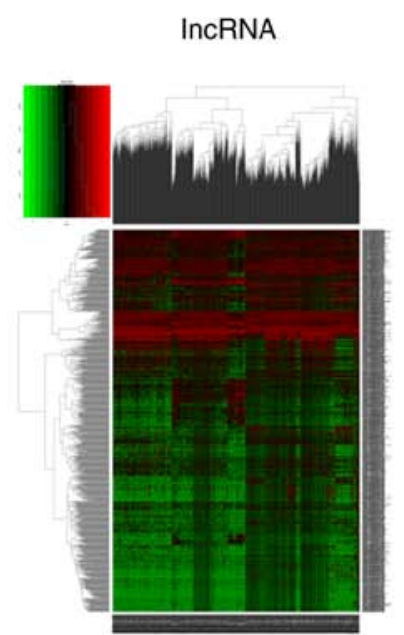

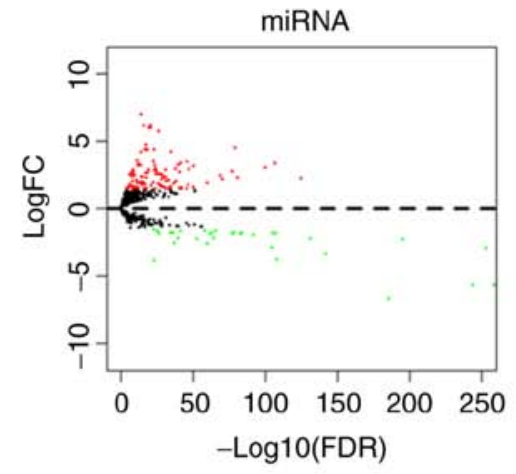

miRNA

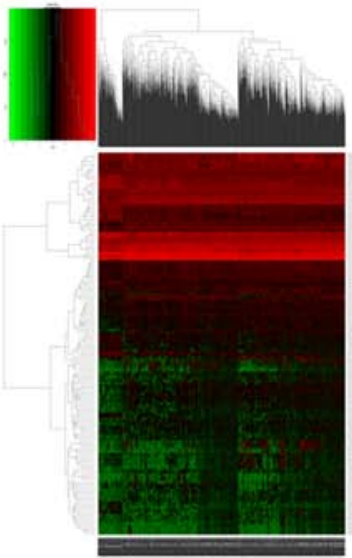

mRNA

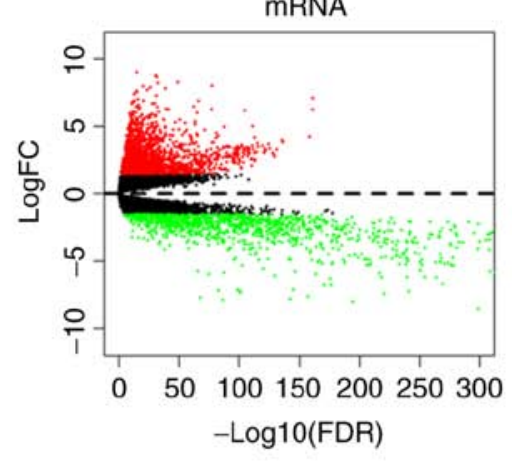

mRNA

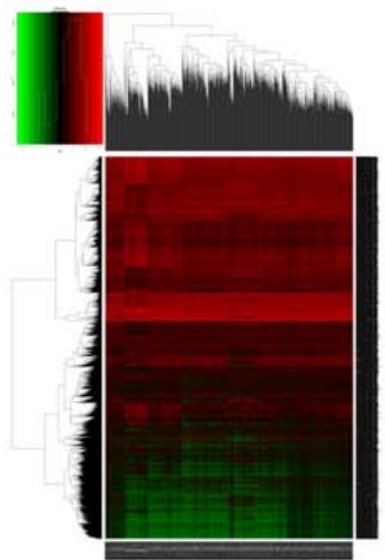

Figure 1. Gene expression analysis of BC data from The Cancer Genome Atlas database. (A) Volcano plots of differentially expressed lncRNAs, miRNAs and mRNAs. The red points in the plots represent upregulated RNAs and the green points represent downregulated RNAs with statistical significance. (B) Heatmaps of differentially expressed RNAs between BC and non-tumor tissues. BC, breast cancer; lncRNA, long non-coding RNA; miRNA, microRNA.

having differential expression profiles in the ceRNA network (Fig. 3A). Based on the plug-in cytoHubba in Cytoscape, the hub network was obtained through the existing network analysis and closeness scores (Fig. 3B). The results included six miRNAs, namely hsa-miR-204, hsa-miR-145, hsa-miR-122, hsa-miR-155, hsa-miR-182 and hsa-miR-183. The lncRNAs involved included LINC00461, AGAP11, LINC00466, LINC00261, MAGI2-AS3, TCL6, ADAMTS9-AS2, AL589642.1 and DLX6-AS1.

Functional analysis of DEmRNAs in the ceRNA network. Using GO and KEGG analysis, the biological functions of the 74 DEmRNAs were investigated. The results indicated that the DEmRNAs were enriched in two GO biological process categories ( $\mathrm{P}<0.05$; Fig. 4A). The main biological process $\mathrm{GO}$ term was 'positive regulation of GTPase activity'. In addition, enriched GO terms based on the analysis of survival curves associated with KM-significant DEmRNAs were identified (Fig. 4B). The network included nine DEmRNAs, which were mainly enriched in 'positive regulation of epithelial cell proliferation'.

From KEGG analysis, four main enriched pathways were determined (Table I and Fig. 5), including the 'mitogen-activated protein kinase (MAPK) signaling pathway', the 'Ras signaling pathway', 'prostate cancer' and the 'FoxO signaling pathway'. Among the four pathways, the 'MAPK pathway' and the 'Ras pathway' are associated with

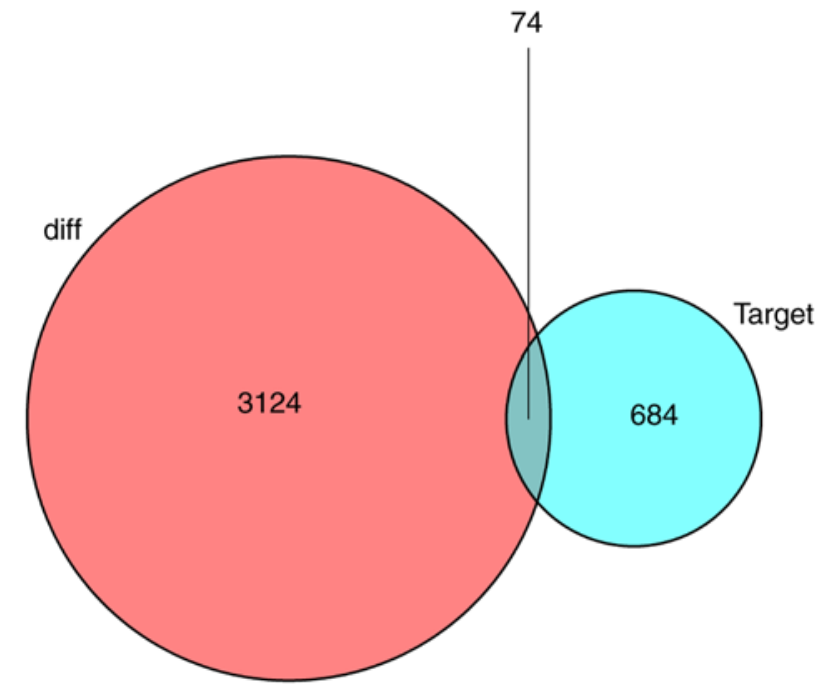

Figure 2. Venn diagram of differentially expressed mRNAs involved in the competing endogenous RNA network. The red circle represents the differentially expressed genes, and the blue circle represents the target genes of miRNAs in the competing endogenous RNA network.

BC progression $(3,30)$. In addition, 'prostate cancer' is linked to tumor-related pathways (32), whereas the 'FoxO signaling pathway' is associated with apoptosis, cell-cycle control and glucose metabolism (33). 
A

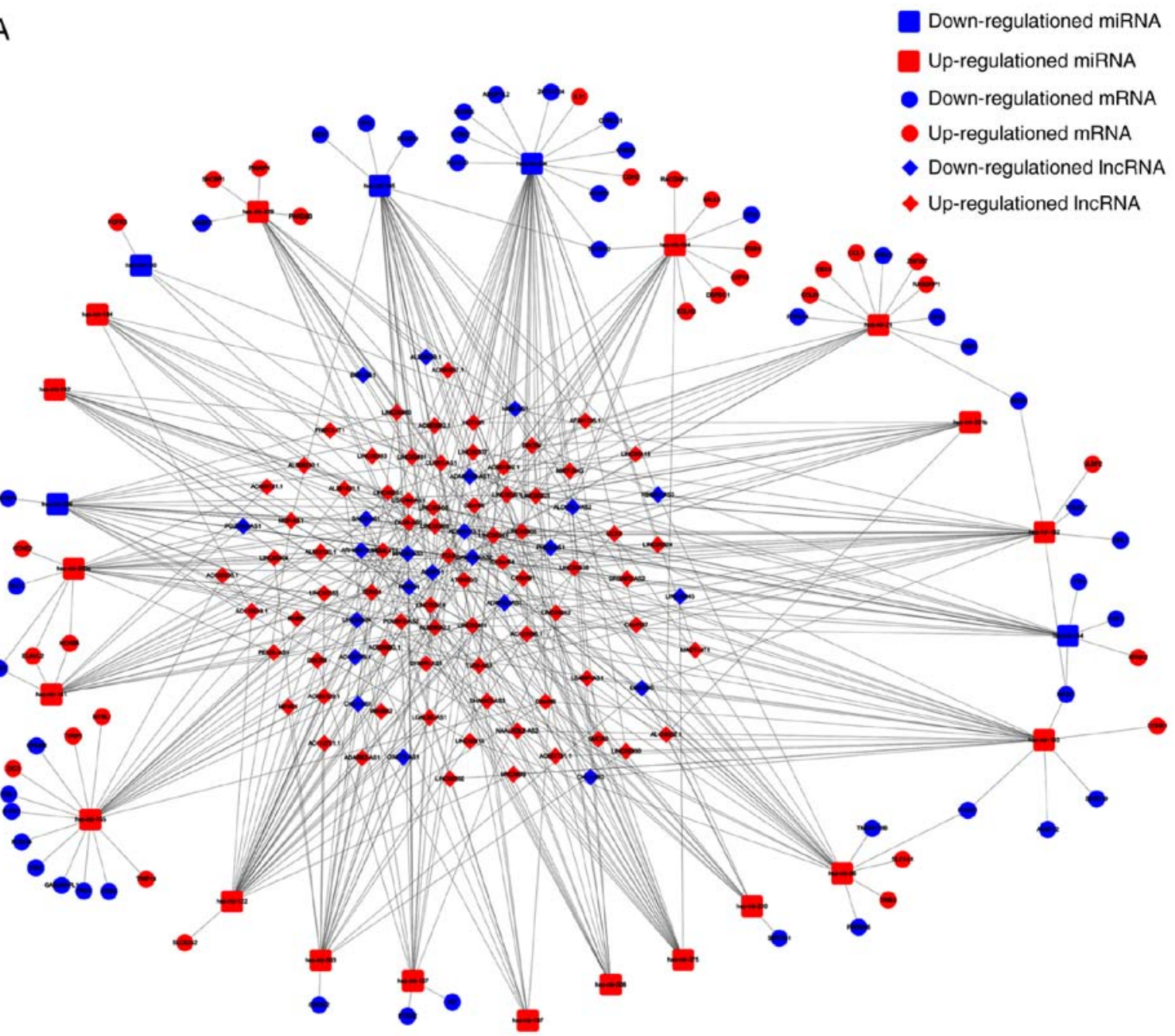

B

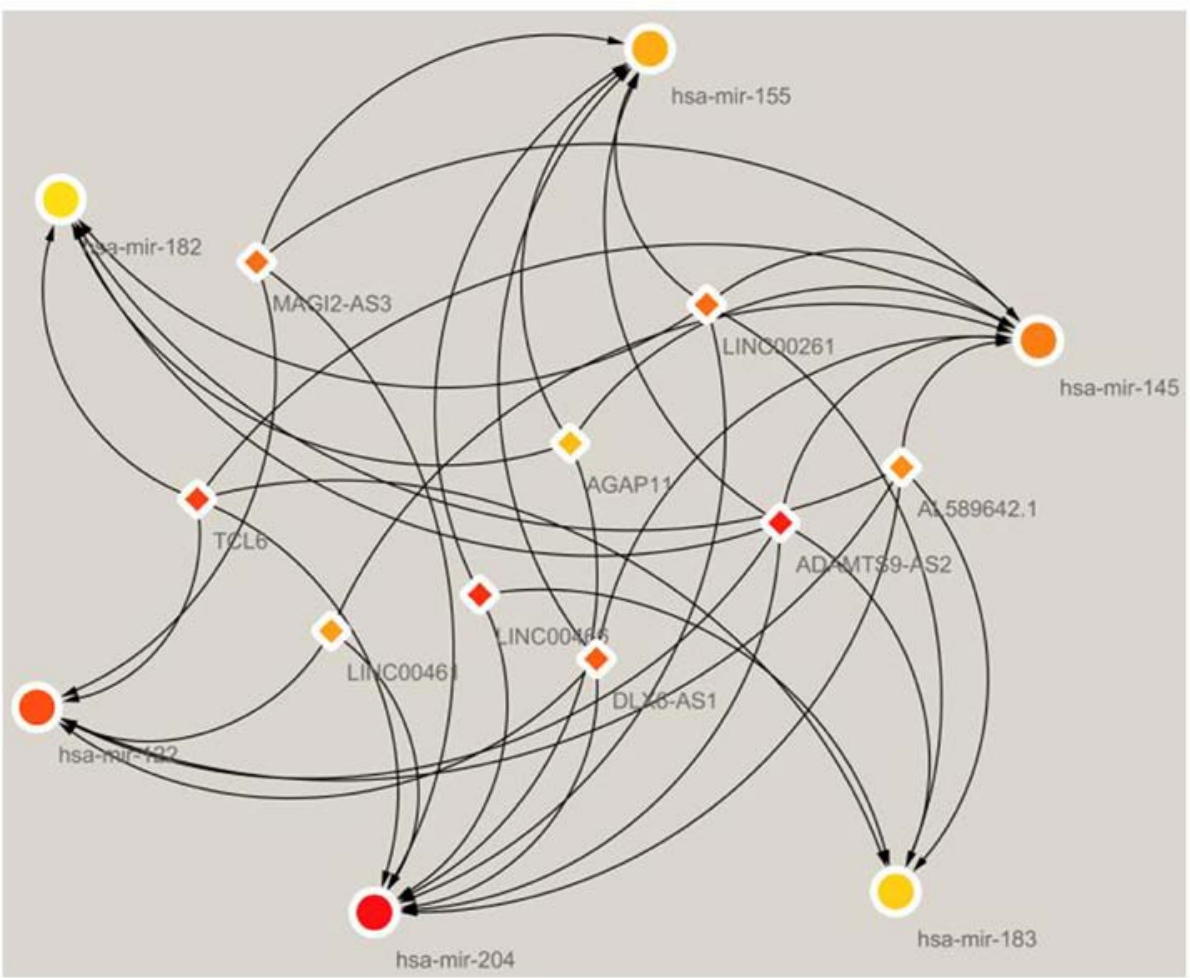

Figure 3. Schematic of the ceRNA network of lncRNA-miRNA-mRNA in breast cancer. (A) The complete network is shown, with diamonds indicating IncRNAs, rounded rectangles indicating miRNAs, and ellipses indicating mRNAs. The red and blue nodes represent upregulation and downregulation, respectively. (B) The hub closeness network involved in the ceRNA network. ceRNA, competing endogenous RNA; lncRNA, long non-coding RNA; miRNA, microRNA. 
A
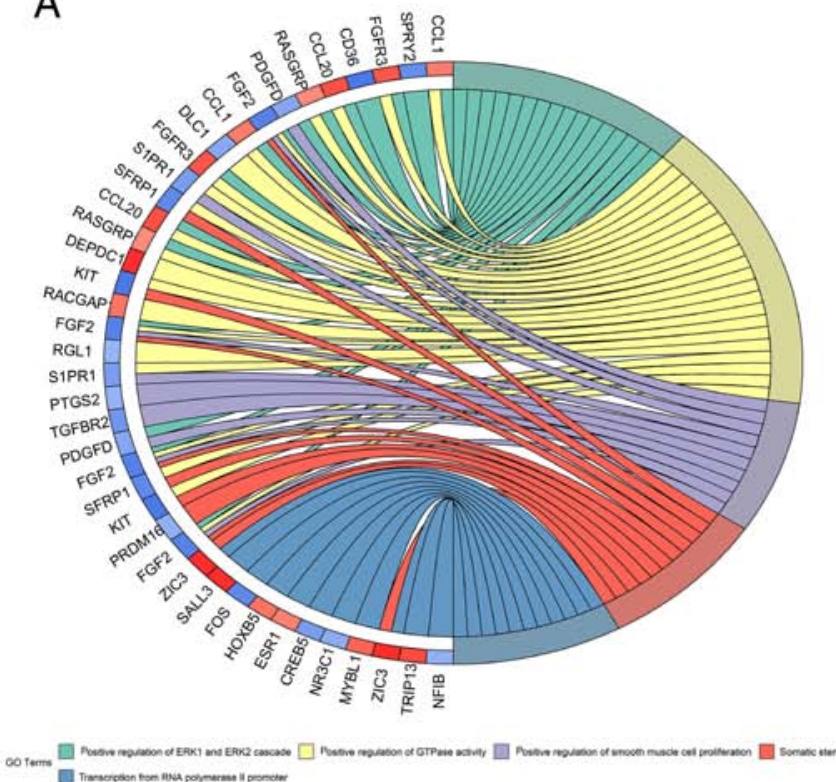

B

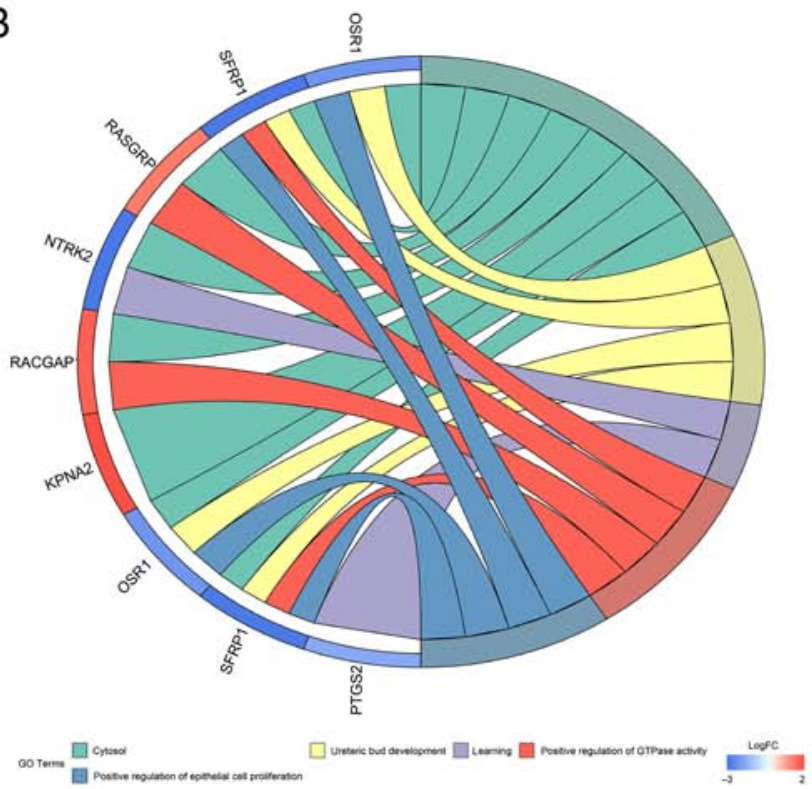

Figure 4. GO enrichment analysis. (A) Enriched GO biological process terms of DEmRNAs involved in the ceRNA network. (B) Enriched GO biological process terms of DEmRNAs involved in the ceRNA network and significantly affecting prognosis by survival analysis. GO, gene ontology; DE, differentially expressed; ceRNA, competing endogenous RNA.

Survival-associated DERNAs in the ceRNA network. KM analysis was performed to investigate the association between DERNAs (DElncRNAs, DEmRNAs and DEmiRNAs) in the ceRNA network and the prognosis of patients with $\mathrm{BC}$, thereby obtaining a prognostic signature for each DERNA.

In total, 6 out of the total 97 DElncRNAs were significantly associated with the rate of overall survival. Among them, three DElncRNAs (INC AC112721.1, LINC00536 and MIR7-3HG) were negatively associated with OS, while the other three (ADAMTS9-AS1, AL356479.1 and LINC00466) were positively associated with OS (Fig. 6A).

In addition, 9 out of the total 74 DEmRNAs were significantly associated with the rate of overall survival. Among them, four DEmRNAs [importin subunit $\alpha 2$ (KPNA2), Rac GTPase-activating protein 1 (RACGAP1), Shc binding and spindle associated 1 (SHCBP1) and zinc finger protein 367 (ZNF367)] were negatively associated with OS, while the remaining five DEmRNAs [tropomyosin receptor kinase B (NTRK2), ORS1, prostaglandin-endoperoxidase synthase 2 (PTGS2), RAS guanyl-releasing protein 1 (RASGRP1) and secreted frizzled-related protein 1 (SFRP1)] were positively associated with OS (Fig. 6B).

Finally, 2 out of the total 24 DEmiRNAs were significantly associated with the rate of OS. The results demonstrated that hsa-miR-301b was negatively associated with OS, while hsa-miR-204 was positively associated with OS (Fig. 6C).

\section{Discussion}

$\mathrm{BC}$ is a common gynecological malignancy; the incidence of this disease is increasing (3). Despite the combined use of surgery, chemotherapy, radiotherapy and endocrine therapy, $\mathrm{BC}$ remains a major cause of cancer-associated mortality in females (34). To improve the clinical status of patients with $\mathrm{BC}$, and develop additional methods for the diagnosis, treat- ment and prognosis of this disease, it is crucial to understand the regulatory mechanism underlying its occurrence and development. The study of prognostic markers associated with $\mathrm{BC}$ may aid early detection and individualized treatment.

Recently, research into the IncRNA-miRNA-mRNA network has attracted increasing attention. Non-coding (nc) RNAs include various forms of RNA, which are categorized into lncRNAs and short ncRNAs. As short-chain ncRNAs, miRNAs are $\sim 22$ nucleotides in length and bind to sequences with partial complementarity to RNA transcripts to act as negative regulators of target gene expression (35). IncRNAs are defined as transcripts $>200$ nucleotides in length with no protein-coding functions (36). Denzler et al (37) proposed the 'competitive endogenous RNA' hypothesis, suggesting that ceRNAs could regulate miRNAs. Salmena et al (7) reported that all types of RNAs can compete with each other for miRNAs, resulting in large-scale transcription crosstalk throughout the transcriptome.

Investigation into ceRNAs and ceRNA networks may provide insight into the processes underlying certain diseases and aid the development of novel therapeutic strategies. The imbalance in lncRNA expression is associated with tumorigenesis, metastasis and prognosis of various types of cancer $(14,16,20,38)$, suggesting that lncRNAs may be potential biomarkers of cancer. In order to evaluate the systematic biological function of the DElncRNAs in the ceRNA network, the present study investigated the association between DElncRNAs and OS. To comprehensively understand how the IncRNA-associated ceRNA network affects BC, large-scale sequencing data of patients with $\mathrm{BC}$ were obtained for analysis from TCGA. DERNAs were detected and a IncRNA-miRNA-mRNA network was constructed based on the prediction of associated tumor-specific biological processes. In total, 97 lncRNA, 22 miRNA and 74 mRNA nodes in the ceRNA networks were identified to be differentially expressed. 
Table I. Kyoto Encyclopedia of Genes and Genomes pathway enrichment analysis of the differentially enriched mRNAs.

\begin{tabular}{|c|c|c|c|c|c|}
\hline $\begin{array}{l}\text { Pathway } \\
\text { ID }\end{array}$ & Description & Genes involved & Count & P-value & $\begin{array}{c}\text { Adjusted } \\
\text { P-value (FDR) }\end{array}$ \\
\hline hsa04010 & MAPK signaling pathway & $\begin{array}{l}\text { TGFBR2, KIT, FGF2, PDGFD, FOS, } \\
\text { NTRK2, FGFR3, RASGRP1 }\end{array}$ & 8 & $<0.001$ & 0.014 \\
\hline hsa05215 & Prostate cancer & FOXO1, ERG, CREB5, PDGFD, CCNE2 & 5 & $<0.001$ & 0.014 \\
\hline hsa04014 & Ras signaling pathway & $\begin{array}{l}\text { KIT, FGF2, RGL1, PDGFD, NTRK2, } \\
\text { FGFR3, RASGRP1 }\end{array}$ & 7 & $<0.001$ & 0.014 \\
\hline hsa04068 & FoxO signaling pathway & $\begin{array}{l}\text { TGFBR2, FOXO1, GABARAPL1, } \\
\text { S1PR1, CCNB1 }\end{array}$ & 5 & $<0.001$ & 0.032 \\
\hline
\end{tabular}

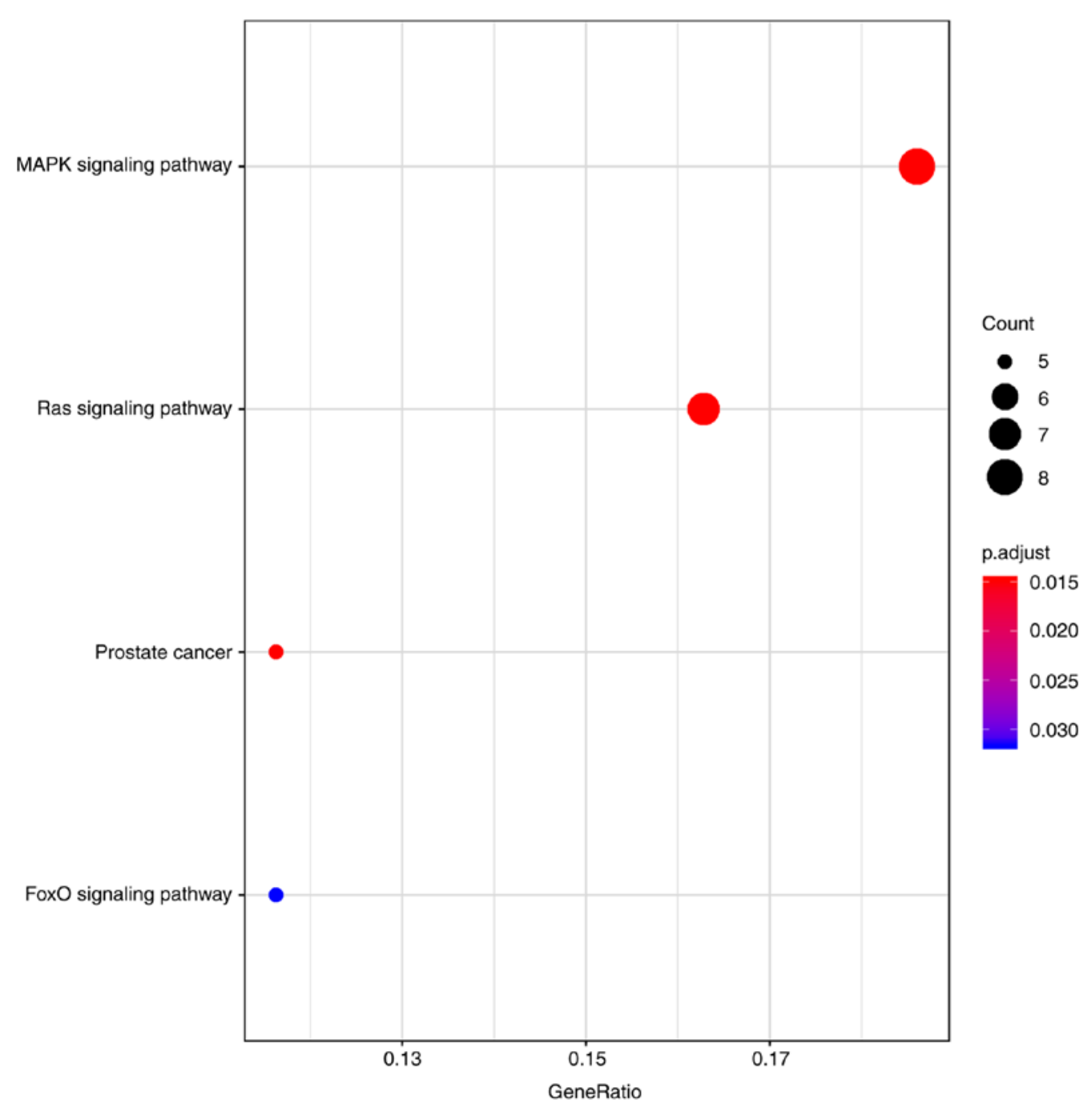

Figure 5. Top 4 enriched Kyoto Encyclopedia of Genes and Genomes pathways of differentially expressed mRNAs involved in the competing endogenous RNA network. MAPK, mitogen-activated protein kinase; FoxO, forkhead box O.

In addition, the association between DElncRNAs and OS, and the biological role of DElncRNAs in ceRNA networks were investigated. In the present study, nine DEmRNAs (KPNA2, NTRK2, ORS1, PTGS2, RACGAP1, RASGRP1, SFRP1, SHCBP1 and ZNF367), six DElncRNAs (INC AC112721.1, ADAMTS9-AS1, AL356479.1, LINC00466, LINC00536 and MIR7-3HG), and two DEmiRNAs (hsa-miR-204,
hsa-miR-301b) were associated with OS; thus, these DERNAs may serve as potential prognostic biomarkers of OS in patients with BC.

The regulation of miRNAs is a critical process associated with tumor-related pathways involved in oncogenesis and tumor progression (39). It has been reported that a higher grade of clear cell renal cell carcinoma is correlated with a concomitant 
A
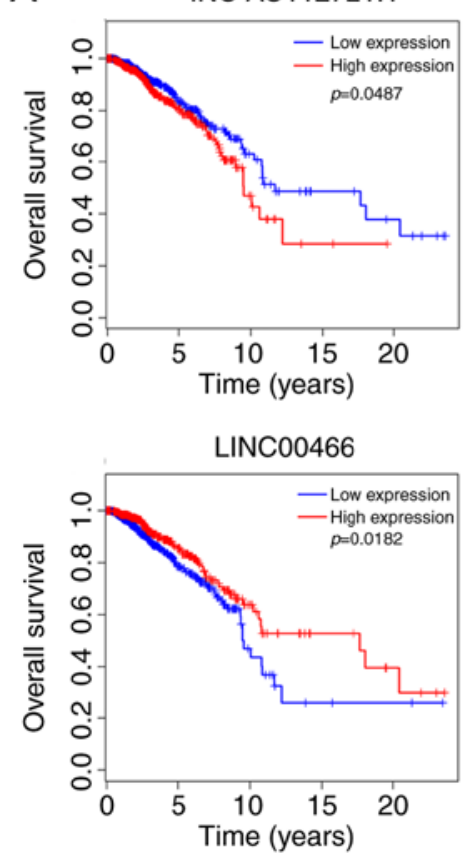

B
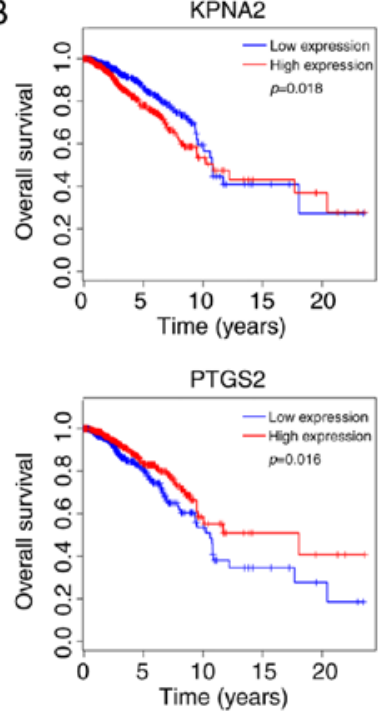

SFRP1

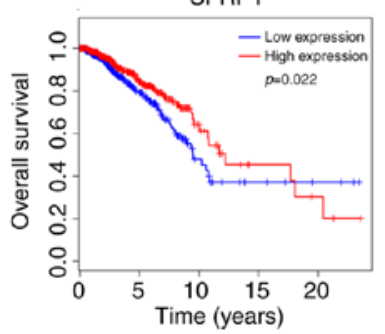

ADAMTS9-AS1

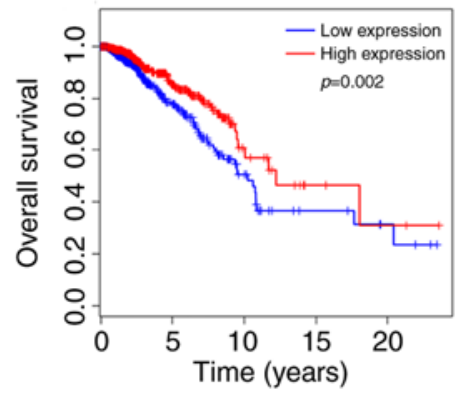

LINC00536

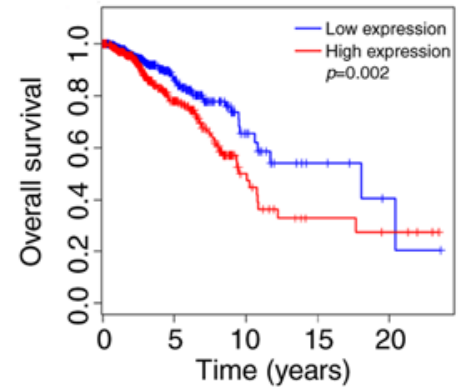

NTRK2
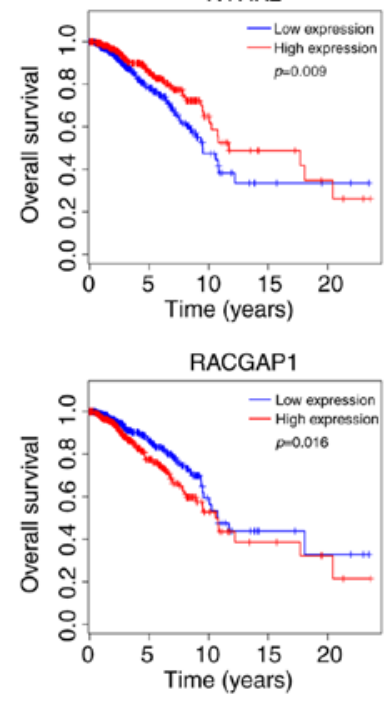

SHCBP1

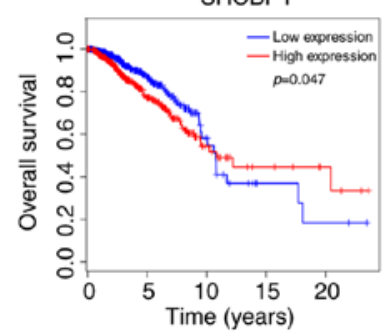

AL356479.1
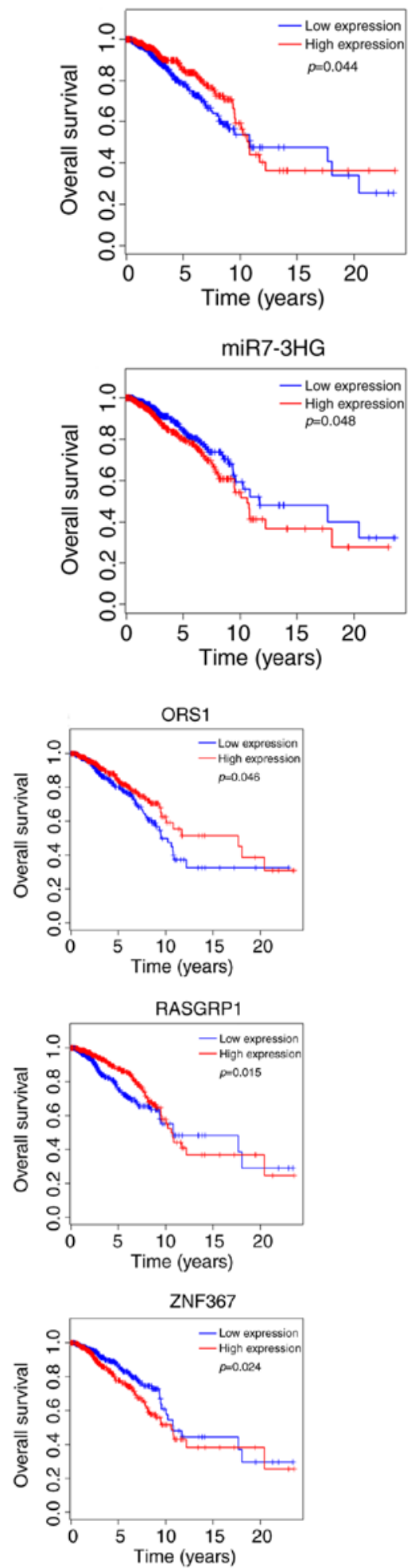

C hsa-miR-204
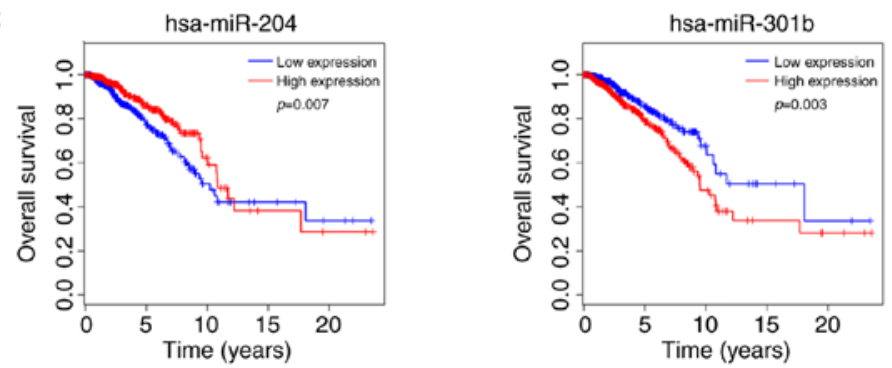

Figure 6. Kaplan-Meier survival curves of differentially expressed (A) long non-coding RNAs, (B) mRNAs and (C) microRNAs significantly associated with overall survival in breast cancer. Table I. Kyoto Encyclopedia of Genes and Genomes pathway enrichment analysis of the differentially enriched mRNAs. 
decrease in miR-204 expression (40,41). Ying et al (42) revealed that miR-204 suppresses the stem cell-associated phenotype, and the self-renewal and migration potentials of glioma cells by targeting SRY-box transcription factor 4 and the EPH receptor B2. Thus, loss of miR-204 expression enhances tumor migration. Shen et al (43) suggested that miR-204 regulates the biological behavior of BC cells by directly targeting forkhead box A1, acting as a tumor suppressor in BC. These reports are consistent with the current results, in which the increased expression of miR-204 was associated with improved overall survival in patients with $\mathrm{BC}$. The current results also demonstrated that upregulated hsa-miR-301b was associated with poor survival in patients with BC. Fort et al (44) revealed that the miR-130b/301b cluster serves a protumorigenic role in prostate cancer.

In the presentstudy, increasedexpression of ADAMTS9-AS1, AL356479.1 and LINC00466 was positively associated with prognosis, while the reduced expression of the remaining three lncRNAs (INC AC112721.1, LINC00536 and MIR7-3HG) was associated with improved prognosis. As an antisense lncRNA, ADAMTS9-AS1 serves crucial roles in the progression and prognosis of carcinoma (45). ADAMTS9-AS1 was determined to be associated with the prognosis of patients with bladder cancer $(46,47)$. Xing et al (48) suggested that ADAMTS9-AS1 may be a marker for predicting the prognosis of colorectal carcinoma. Li et al (49) reported that ADAMTS9-AS1 may be indispensable in the development of the ectoderm and epithelial cells, and can be effectively employed for determining the risk of esophageal cancer development. In addition, it was indicated that ADAMTS9-AS1 serves as a risk-predicting IncRNA in ovarian cancer (50). Analysis of BC data revealed ADAMTS9-AS1 and LINC00536 to be prognostic markers for BC (50). These previous findings were consistent with the results of the present study. To the best of our knowledge, no studies have reported the roles of AC112721.1, AL356479.1, LINC00466 and MIR7-3HG in cancer.

Accumulating evidence has demonstrated that miRNAs serve an important role in cancer. In the ceRNA network, the present study reported that the upregulated expression of LINC00466 was associated with downregulation of hsa-miR-204 and hsa-miR-144; and MIR7-3HG was determined to downregulate hsa-miR-204 and hsa-miR-145. Several studies have reported that the levels of hsa-miR-204 were decreased in certain types of cancer, including gastric cancer (51) and lung cancer (52). Based on TCGA data of 1,077 BC tissue samples, Alhawaj et al (53) determined that miR-204-5p was markedly downregulated when compared with 104 normal tissue samples. Liu et al (54) demonstrated that trichostatin A and tamoxifen inhibited BC cell growth via miR-204 and estrogen receptor (ER) $\alpha$-mediated suppression of the AKT/mTOR pathway, suggesting that miR-204 may be associated with tumor growth and with sensitivity to chemotherapeutic agents. The present study proposed the involvement of the LINC00466-hsa-miR-204-NTRK2 axis in BC. Thus, LINC00466 and MIR7-3HG may be crucial for the progression of tumors by interacting with hsa-miR-204. In addition, hsa-miR-144 and hsa-miR-145 exhibit inverse expression profiles in $\mathrm{BC}$ tissues (55-57).

Combining the results of the hub networks based on analysis with the plug-in cytoHubba in Cytoscape, the present study determined that hsa-miR-155 and AGAP11 had a high degree of closeness, and exhibited significance from GO analysis. Hsa-miR-155 is a multifunctional small RNA located in chromosome 21 , and is involved in a variety of biological and pathological processes (58). Volinia et al (59) reported that miRNAs served complex roles in tumors; network analysis indicated that the majority of miRNAs were linked to hsa-miR-155 within transgenic mice with miR-155-induced acute lymphocytic leukemia (59). Chuang et al (60) identified that the increased expression of hsa-miR-155-5p was a poor prognostic marker in acute myeloid leukemia. Braun et al (61) revealed that germline polymorphisms at AGAP11 were associated with stage-adjusted survival in ovarian cancer. In the current network, hsa-miR-155 was highly expressed, while AGAP11 was expressed at low levels, and may be a prognostic marker in BC. Additionally, 74 DEmRNAs were identified in the current ceRNA network. GO analysis revealed that the main enriched GO biological processes were 'positive regulation of GTPase activity', 'positive regulation of ERK1 and ERK2 cascade' and 'transcription from RNA polymerase II promoter'. Analysis of the enriched GO networks of the KM-significant DEmRNAs revealed that nine DEmRNAs were mainly enriched in 'cytosol' and 'positive regulation of epithelial cell proliferation'. Among the nine DEmRNAs, upregulated RASGRP1 expression was demonstrated to be associated with favorable outcome in BC. As a guanine nucleotide exchange factor, RASGRP1 can sensitize Ras and ERK/MAPK cascades. Alterations in RASGRP1 expression have been associated with a variety of diseases, including systemic lupus erythematosus (62), hepatotoxicity (63), and cancer $(64,65)$. Upregulated RASGRP1 expression correlates with improved clinical outcomes in patients with colorectal cancer, and may induce a negative feedback loop to suppress proliferative epidermal growth factor receptor/son of sevenless homolog $1 /$ Ras signaling (64). RASGRP1 may be a novel therapeutic target for the treatment of hepatocellular carcinoma (66). Wang et al (67) reported a positive correlation between RASGRP1 overexpression and survival in triple-negative breast cancer. Some studies have reported that RASGRP1 is associated with the acquired drug resistance of tumors $(68,69)$. In addition, seven other genes identified in the present study (KPNA2, NTRK2, PTGS2, RACGAP1, SFRP1, SHCBP1 ZNF367) have been reported to be associated with the prognosis of tumors (70-75).

Pathway analysis suggested that DEGs were mainly involved in the 'MAPK signaling pathway' and the 'Ras signaling pathway' in the present study. Additionally, the present results demonstrated that RASGRP1 was enriched in the 'MAPK signaling pathway' and the 'Ras signaling pathway'. MAPKs are a class of serine/threonine protein kinases in cells, and the MAPK signaling pathway is present in most types of cells. MAPK signaling serves an important role in transducing extracellular signals into cells and their nuclei, and induces various cellular biological processes, including cell differentiation, proliferation and apoptosis. Numerous studies have demonstrated that the MAPK signaling pathway is associated with the development of BC (76-79). Yang et al (78) indicated that $\mathrm{C}-\mathrm{C}$ motif chemokine ligand 28 has been associated with the proliferation and metastasis of $\mathrm{BC}$ via the 
MAPK-mediated anti-apoptotic and metastasis signaling pathways. The androgen receptor pathway is a potential target for the treatment of $\mathrm{BC}$, and has been reported to exhibit crosstalk with the MAPK pathway (77). Previously, the MAPK signaling pathway was demonstrated to be involved in the development of drug resistance in tumors (78). Jia et al (79) reported that Kruppel-like factor 4 (KLF4) could enhance the response of BC cells to tamoxifen by inhibiting the MAPK signaling pathway, indicating that targeting KLF4/MAPK signaling may be a potential therapeutic strategy for treating BC. RAS is one of the most commonly mutated genes linked to human cancer. Anticancer inhibitors targeting the RAS signaling pathway are potential therapeutic agents for the treatment of cancers; however, further investigation is required. The abnormal activation of the Ras/ERK pathway mediates the occurrence and invasiveness of $\mathrm{BC}$, which is notably common in BC. Ras activation is a crucial determinant of the transmission and poor prognosis of $\mathrm{ER} \alpha^{+} /$luminal $\mathrm{BC}(80,81)$.

To the best of our knowledge, the present study is the first to report the aberrant expression of INC AC112721.1, AL356479.1, LINC00466 and MIR7-3HG in BC, indicating their potential prognostic value in $\mathrm{BC}$. The present study proposed that LINC00466 and MIR7-3HG interact with hsa-miR-204, which may be involved in the development of BC; to the best of our knowledge, this has not been reported previously. Of note, further bioinformatics analysis of the ceRNA network in BC may aid future investigations. The current results determined that the genes associated with survival in BC were enriched in the 'MAPK signaling pathway', which has been reported to be associated with drug resistance. Our group aims to further investigate the pathology of $\mathrm{BC}$ via in vivo and in vitro experiments in the future.

\section{Acknowledgements}

Not applicable.

\section{Funding}

This work was supported by the Science and Education for Health Foundation of Suzhou for Youth (grant nos. kjxw2018030 and kjxw2018032), the Science and Technology Project Foundation of Suzhou (grant no. SS201651), the Education Research Project Foundation of Nanjing Medical University (grant no. FZS-ZD-201701) and the Key Medical Disciplines in Jiangsu Province (grant no. ZDXKC2016007).

\section{Availability of data and materials}

The datasets used and/or analyzed during the present study are available from the corresponding author on reasonable request.

\section{Authors' contributions}

JJW, YQH and WS carried out data acquisition and processing, and were the major contributors in writing the manuscript. YFL and HW made contributions to data analysis, interpretation and figure editing. WJW and MH directed the whole study, and revised the manuscript. All authors read and approved the final manuscript.

\section{Ethics approval and consent to participate}

Not applicable.

\section{Patient consent for publication}

Not applicable.

\section{Competing interests}

The authors declare that they have no competing interests.

\section{References}

1. Siegel R, Ma J, Zou Z and Jemal A: Cancer statistics, 2014. CA Cancer J Clin 64: 9-29, 2014.

2. Wang Y, Zhou Y, Yang Z, Chen B, Huang W, Liu Y and Zhang Y: MiR-204/ZEB2 axis functions as key mediator for MALAT1-induced epithelial-mesenchymal transition in breast cancer. Tumour Biol 39: 1010428317690998, 2017.

3. Kroenke CH, Michael YL, Poole EM, Kwan ML, Nechuta S, Leas E, Caan BJ, Pierce J, Shu XO, Zheng Y and Chen WY: Postdiagnosis social networks and breast cancer mortality in the after breast cancer pooling project. Cancer 123: 1228-1237, 2017.

4. Luschin $\mathrm{G}$ and Habersack M: Oral information about side effects of endocrine therapy for early breast cancer patients at initial consultation and first follow-up visit: An online survey. Health Commun 29: 421-426, 2014.

5. Cheng Y, Tao L, Xu J, Li Q, Yu J, Jin Y, Chen Q, Xu Z, Zou Q and Liu X: CD44/cellular prion protein interact in multidrug resistant breast cancer cells and correlate with responses to neoadjuvant chemotherapy in breast cancer patients. Mol Carcinog 53: 686-697, 2014.

6. Bao L, Messer K, Schwab R, Harismendy O, Pu M, Crain B, Yost S, Frazer KA, Rana B, Hasteh F, et al: Mutational profiling can establish clonal or independent origin in synchronous bilateral breast and other tumors. PLoS One 10: e0142487, 2015.

7. Salmena L, Poliseno L, Tay Y, Kats L and Pandolfi PP: A ceRNA hypothesis: The Rosetta Stone of a hidden RNA language? Cell 146: 353-358, 2011.

8. Rapicavoli NA, Qu K, Zhang J, Mikhail M, Laberge RM and Chang HY: A mammalian pseudogene lncRNA at the interface of inflammation and anti-inflammatory therapeutics. Elife 2: e00762, 2013.

9. Mercer TR, Dinger ME and Mattick JS: Long non-coding RNAs: Insights into functions. Nat Rev Genet 10: 155-159, 2009.

10. Ponting CP, Oliver PL and Reik W: Evolution and functions of long noncoding RNAs. Cell 136: 629-641, 2009.

11. Anamaria N, Soumillon M, Warnefors M, Liechti A, Daish T, Zeller U, Baker JC, Grützner F and Kaessmann H: The evolution of lncRNA repertoires and expression patterns in tetrapods. Nature 505: 635-640, 2014.

12. Xue $B$ and He L: An expanding universe of the non-coding genome in cancer biology. Carcinogenesis 35: 1209-1216, 2014.

13. Xie C, Yuan J, Li H, Li M, Zhao G, Bu D, Zhu W, Wu W, Chen R and Zhao Y: NONCODEv4: Exploring the world of long non-coding RNA genes. Nucleic Acids Res 42 (Database Issue): D98-D103, 2014.

14. Kumar M.S, Armenteros-Monterroso E, East P, Chakravorty P, Matthews N, Winslow MM and Downward J: HMGA2 functions as a competing endogenous RNA to promote lung cancer progression. Nature 505: 212-217, 2014.

15. Wang $C$, Chen L, Yang $Y$, Zhang $M$ and Wong $G$ : Identification of bladder cancer prognostic biomarkers using an ageing gene-related competitive endogenous RNA network. Oncotarget 8: 111742-111753, 2017.

16. Zhou M, Wang X, Shi H, Cheng L, Wang Z, Zhao H, Yang L and Sun J: Characterization of long non-coding RNA-associated ceRNA network to reveal potential prognostic lncRNA biomarkers in human ovarian cancer. Oncotarget 7: 12598-12611, 2016.

17. Chiu YC, Hsiao TH, Chen Y and Chuang EY: Parameter optimization for constructing competing endogenous RNA regulatory network in glioblastoma multiforme and other cancers. BMC Genomics 16 (Suppl 4): S1, 2015. 
18. Wu Q, Xiang S, Ma J, Hui P, Wang T, Meng W, Shi M and Wang Y: Long non-coding RNA CASC15 regulates gastric cancer cell proliferation, migration and epithelial mesenchymal transition by targeting CDKN1A and ZEB1. Mol Oncol 12: 799-813, 2018

19. Yao K, Wang Q, Jia J and Zhao H: A competing endogenous RNA network identifies novel mRNA, miRNA and lncRNA markers for the prognosis of diabetic pancreatic cancer. Tumour Biol 39: 1010428317707882, 2017.

20. Shan Y, Ma J, Pan Y, Hu J, Liu B and Jia L: LncRNA SNHG7 sponges miR-216b to promote proliferation and liver metastasis of colorectal cancer through upregulating GALNT1. Cell Death Dis 9: 722, 2018

21. Paci P, Colombo T and Farina L: Computational analysis identifies a sponge interaction network between long non-coding RNAs and messenger RNAs in human breast cancer. BMC Syst Biol 8: 83, 2014.

22. Berger AC, Korkut A, Kanchi RS, Hegde AM, Lenoir W, Liu W, Liu Y, Fan H, Shen H, Ravikumar V, et al: A comprehensive pan-cancer molecular study of gynecologic and breast cancers. Cancer Cell 33: 690-705.e9, 2018.

23. Zhao W, Luo J and Jiao S: Comprehensive characterization of cancer subtype associated long non-coding RNAs and their clinical implications. Sci Rep 4: 6591, 2014

24. Jeggari A, Marks DS and Larsson E: miRcode: A map of putative microRNA target sites in the long non-coding transcriptome. Bioinformatics 28: 2062-2063, 2012

25. Li JH, Liu S, Zhou H, Qu LH and Yang JH: StarBase v2.0: Decoding miRNA-ceRNA, miRNA-ncRNA and protein-RNA interaction networks from large-scale CLIP-Seq data. Nucleic Acids Res 42 (Database Issue): D92-D97, 2014.

26. Wong N and Wang X: miRDB: An online resource for microRNA target prediction and functional annotations. Nucleic Acids Res 43 (Database Issue): D146-D152, 2015.

27. Chou CH, Shrestha S, Yang CD, Chang NW, Lin YL, Liao KW, Huang WC, Sun TH, Tu SJ, Lee WH, et al: MiRTarBase update 2018: A resource for experimentally validated microRNA-target interactions. Nucleic Acids Res 46: D296-D302,2018.

28. Agarwal V, Bell GW, Nam JW and Bartel DP: Predicting effective microRNA target sites in mammalian mRNAs. Elife: 4 2015 doi: 10.7554/eLife.05005.

29. Shannon P, Markiel A, Ozier O, Baliga NS, Wang JT, Ramage D, Amin N, Schwikowski B and Ideker T: Cytoscape: A software environment for integrated models of biomolecular interaction networks. Genome Res 13: 2498-2504, 2003.

30. Dennis G Jr, Sherman BT, Hosack DA, Yang J, Gao W, Lane HC and Lempicki RA: DAVID: Database for Annotation, visualization, and Integrated Discovery. Genome Biol 4: P3, 2003.

31. Aiex RM, Resende MGC and Ribeiro CC: TTT plots: A perl program to create time-to-target plots. Optimization Lett 1: 355-366, 2007.

32. Jia P, Liu Y and Zhao Z: Integrative pathway analysis of genome-wide association studies and gene expression data in prostate cancer. BMC Syst Biol 6 (Suppl 3): S13, 2012.

33. Coomans de Brachène A and Demoulin JB: FOXO transcription factors in cancer development and therapy. Cell Mol Life Sci 73 : $1159-1172,2016$

34. Stagl JM, Bouchard LC, Lechner SC, Blomberg BB Gudenkauf LM, Jutagir DR, Glück S, Derhagopian RP Carver CS and Antoni MH: Long-term psychological benefits of cognitive-behavioral stress management for women with breast cancer: 11-year follow-up of a randomized controlled trial. Cancer 121: 1873-1881, 2015.

35. Haecker I and Renne R: HITS-CLIP and PAR-CLIP advance viral miRNA targetome analysis. Crit Rev Eukaryot Gene Expr 24: 101-116, 2014.

36. Wang K, Guo WX, Li N, Gao CF, Shi J, Tang YF, Shen F, Wu MC, Liu SR and Cheng SQ: Serum LncRNAs profiles serve as novel potential biomarkers for the diagnosis of HBV-positive hepatocellular carcinoma. PLoS One 10: e0144934, 2015

37. Denzler R, Agarwal V, Stefano J, Bartel DP and Stoffel M: Assessing the ceRNA hypothesis with quantitative measurements of miRNA and target abundance. Mol Cell 54: 766-776, 2014.

38. Xia T, Liao Q, Jiang X, Shao Y, Xiao B, Xi Y and Guo J: Long noncoding RNA associated-competing endogenous RNAs in gastric cancer. Sci Rep 4: 6088, 2014.

39. Liu C, Liu R, Zhang D, Deng Q, Liu B, Chao HP, Rycaj K, Takata Y, Lin K, Lu Y, et al: MicroRNA-141 suppresses prostate cancer stem cells and metastasis by targeting a cohort of pro-metastasis genes. Nat Commun 8: 14270, 2017.
40. Mikhaylova O, Stratton Y, Hall D, Kellner E, Ehmer B, Drew AF Gallo CA, Plas DR, Biesiada J, Meller J and Czyzyk-Krzeska MF: VHL-regulated MiR-204 suppresses tumor growth through inhibition of LC3B-mediated autophagy in renal clear cell carcinoma. Cancer Cell 21: 532-546, 2012.

41. Hall DP, Cost NG, Hegde S, Kellner E, Mikhaylova O, Stratton Y, Ehmer B, Abplanalp WA, Pandey R, Biesiada J, et al: TRPM3 and miR-204 establish a regulatory circuit that controls oncogenic autophagy in clear cell renal cell carcinoma. Cancer Cell 26: 738-753, 2014.

42. Ying Z, Li Y, Wu J, Zhu X, Yang Y, Tian H, Li W, Hu B, Cheng SY and Li M: Loss of miR-204 expression enhances glioma migration and stem cell-like phenotype. Cancer Res 73: 990-999, 2013

43. Shen SQ, Huang LS, Xiao XL, Zhu XF, Xiong DD, Cao XM, Wei KL, Chen G and Feng ZB: miR-204 regulates the biological behavior of breast cancer MCF-7 cells by directly targeting FOXA1. Oncol Rep 38: 368-376, 2017.

44. Fort RS, Mathó C, Oliveira-Rizzo C, Garat B, Sotelo-Silveira JR and Duhagon MA: An integrated view of the role of miR-130b/301b miRNA cluster in prostate cancer. Exp Hematol Oncol 7: 10, 2018.

45. Yuan SX, Tao QF, Wang J, Yang F, Liu L, Wang LL, Zhang J, Yang Y, Liu H, Wang F, et al: Antisense long non-coding RNA PCNA-AS1 promotes tumor growth by regulating proliferating cell nuclear antigen in hepatocellular carcinoma. Cancer Lett 349: 87-94, 2014.

46. Zhu N, Hou J, Wu Y, Liu J, Li G, Zhao W, Ma G, Chen B and Song Y: Integrated analysis of a competing endogenous RNA network reveals key lncRNAs as potential prognostic biomarkers for human bladder cancer. Medicine (Baltimore) 97: e11887, 2018.

47. Xia Y, Liu Z, Yu W, Zhou S, Shao L, Song W and Liu M: The prognostic significance of long noncoding RNAs in bladder cancer: A meta-analysis. PLoS One 13: e0198602, 2018.

48. Xing Y, Zhao Z, Zhu Y, Zhao L, Zhu A and Piao D: Comprehensive analysis of differential expression profiles of mRNAs and lncRNAs and identification of a 14-lncRNA prognostic signature for patients with colon adenocarcinoma. Oncol Rep 39: 2365-2375, 2018.

49. Li Z, Yao Q, Zhao S, Wang Y, Li Y and Wang Z: Comprehensive analysis of differential co-expression patterns reveal transcriptional dysregulation mechanism and identify novel prognostic lncRNAs in esophageal squamous cell carcinoma. Onco Targets Ther 10: 3095-3105, 2017.

50. Wang H, Fu Z, Dai C, Cao J, Liu X, Xu J, Lv M, Gu Y, Zhang J, Hua X, et al: LncRNAs expression profiling in normal ovary, benign ovarian cyst and malignant epithelial ovarian cancer. Sci Rep 6: 38983, 2016.

51. Sonohara F, Inokawa Y, Hayashi M, Kodera Y and Nomoto S: Epigenetic modulation associated with carcinogenesis and prognosis of human gastric cancer. Oncol Lett 13: 3363-3368, 2017.

52. Shi L, Zhang B, Sun X, Lu S, Liu Z, Liu Y, Li H, Wang L, Wang X and Zhao C: MiR-204 inhibits human NSCLC metastasis through suppression of NUAK1. Br J Cancer 111: 2316-2327, 2014.

53. Alhawaj R: Heme biosynthesis and metabolism are important contributors to the pathophysiology of chronic hypoxia-induced pulmonary hypertension. Dissertations \& Theses-Gradworks, 2014 http://xueshu.baidu.com/usercenter/paper/show?paperid=c770828 df9516fbf $2613928 \mathrm{c} 9 \mathrm{fbecb} 09 \&$ site $=$ xueshu se\&hitarticle=1.

54. Liu J and Li Y: Trichostatin A and Tamoxifen inhibit breast cancer cell growth by miR-204 and ER $\alpha$ reducing AKT/mTOR pathway. Biochem Biophys Res Commun 467: 242-247, 2015.

55. Vivacqua A, De Marco P, Santolla MF, Cirillo F, Pellegrino M, Panno ML, Abonante S and Maggiolini M: Estrogenic gper signaling regulates mir144 expression in cancer cells and cancer-associated fibroblasts (cafs). Oncotarget 6: 16573-16587, 2015.

56. Liu SY, Li XY, Chen WQ, Hu H, Luo B, Shi YX, Wu TW, Li Y, Kong QZ, Lu HD and Lu ZX: Demethylation of the MIR145 promoter suppresses migration and invasion in breast cancer. Oncotarget 8: 61731-61741, 2017.

57. Muti P, Sacconi A, Hossain A, Donzelli S, Ben Moshe NB, Ganci F, Sieri S, Krogh V, Berrino F, Biagioni F, et al: Downregulation of microRNAs $145-3 p$ and $145-5 p$ is a long-term predictor of postmenopausal breast cancer risk: The ORDET prospective study. Cancer Epidemiol Biomarkers Prev 23: 2471-2481, 2014.

58. Faraoni I, Antonetti FR, Cardone J and Bonmassar E: miR-155 gene: A typical multifunctional microRNA. Biochim Biophys Acta 1792: 497-505, 2009. 
59. Volinia S, Galasso M, Costinean S, Tagliavini L, Gamberoni G, Drusco A, Marchesini J, Mascellani N, Sana ME, Abu Jarour R, et al: Reprogramming of miRNA networks in cancer and leukemia. Genome Res 20: 589-599, 2010.

60. Chuang MK, Chiu YC, Chou WC, Hou HA, Chuang EY and Tien HF: A 3-microRNA scoring system for prognostication in de novo acute myeloid leukemia patients. Leukemia 29: 1051-1059, 2015.

61. Braun R, Finney R, Yan C, Chen QR, Hu Y, Edmonson M, Meerzaman D and Buetow K: Discovery analysis of TCGA data reveals association between germline genotype and survival in ovarian cancer patients. PLoS One 8: e55037, 2013.

62. Yasuda S, Stevens RL, Terada T, Takeda M, Hashimoto T, Fukae J, Horita T, Kataoka H, Atsumi T and Koike T: Defective expression of Ras guanyl nucleotide-releasing protein 1 in a subset of patients with systemic lupus erythematosus. J Immunol 179: 4890-4900, 2007.

63. Horinouchi M, Yagi M, Imanishi H, Mori T, Yanai T, Hayakawa A, Takeshima Y, Hijioka M, Okamura N, Sakaeda T, et al: Association of genetic polymorphisms with hepatotoxicity in patients with childhood acute lymphoblastic leukemia or lymphoma. Pediatr Hematol Oncol 27: 344-354, 2010.

64. Depeille P, Henricks LM, van de Ven RA, Lemmens E, Wang CY, Matli M, Werb Z, Haigis KM, Donner D, Warren R and Roose JP: RasGRP1 opposes proliferative EGFR-SOS1-Ras signals and restricts intestinal epithelial cell growth. Nat Cell Biol 17: 804-815, 2015.

65. Sharma A,Fonseca LL, Rajani C, Yanagida JK, Endo Y, Cline JM, Stone JC, Ji J, Ramos JW and Lorenzo PS: Targeted deletion of RasGRP1 impairs skin tumorigenesis. Carcinogenesis 35: 1084-1091, 2014

66. Zhang X, Zhuang H, Han F, Shao X, Liu Y, Ma X, Wang Z, Qiang Z and Li Y: Sp1-regulated transcription of RasGRP1 promotes HCC proliferation. Liver Int 38: 2006-2017, 2018

67. Wang S, Beeghly-Fadiel A, Cai Q, Cai H, Guo X, Shi L, Wu J, Ye F, Qiu Q, Zheng Y, et al: Gene expression in triple-negative breast cancer in relation to survival. Breast Cancer Res Treat 171: 199-207, 2018.

68. Lauchle JO, Kim D, Le DT, Akagi K, Crone M, Krisman K, Warner K, Bonifas JM, Li Q, Coakley KM, et al: Response and resistance to MEK inhibition in leukaemias initiated by hyperactive Ras. Nature 461: 411-414, 2009.

69. Ding H, Peterson KL, Correia C, Koh B, Schneider PA, Nowakowski GS and Kaufmann SH: Histone deacetylase inhibitors interrupt HSP90 RASGRP1 and HSP90 CRAF interactions to upregulate BIM and circumvent drug resistance in lymphoma cells. Leukemia 31: 1593-1602, 2017.

70. Mortezavi A, Hermanns T, Seifert HH, Baumgartner MK, Provenzano M, Sulser T, Burger M, Montani M, Ikenberg K, Hofstädter F, et al: KPNA2 expression is an independent adverse predictor of biochemical recurrence after radical prostatectomy. Clin Cancer Res 17: 1111-1121, 2011.
71. Sengel-Turk CT, Hascicek C, Bakar F and Simsek E: Comparative evaluation of nimesulide-loaded nanoparticles for anticancer activity against breast cancer cells. Aaps PharmSciTech 18: 393-403, 2017.

72. Hass HG, Vogel U, Scheurlen M and Jobst J: Gene-expression Analysis identifies specific patterns of dysregulated molecular pathways and genetic subgroups of human hepatocellular carcinoma. Anticancer Res 36: 5087-5095, 2016.

73. Buhmeida A, Merdad A, Al-Maghrabi J, Al-Thobaiti F, Ata M, Bugis A, Syrjänen K, Abuzenadah A, Chaudhary A, Gari M, et al: RASSF1A methylation is predictive of poor prognosis in female breast cancer in a background of overall low methylation frequency. Anticancer Res 31: 2975-2981, 2011.

74. Tao HC, Wang HX, Dai M, Gu CY, Wang Q, Han ZG and Cai B Targeting SHCBP1 inhibits cell proliferation in human hepatocellular carcinoma cells. Asian Pac J Cancer Prev 14: 5645-5650, 2013.

75. Li WX, He K, Tang L, Dai SX, Li GH, Lv WW, Guo YC, An SQ, Wu GY, Liu D and Huang JF: Comprehensive tissue-specific gene set enrichment analysis and transcription factor analysis of breast cancer by integrating 14 gene expression datasets. Oncotarget 8: 6775-6786, 2016.

76. Yang XL, Liu KY, Lin FJ, Shi HM and Ou ZL: CCL28 promotes breast cancer growth and metastasis through MAPK-mediated cellular anti-apoptosis and pro-metastasis. Oncol Rep 38: 1393-1401, 2017

77. Kono M, Fujii T, Lim B, Karuturi MS, Tripathy D and Ueno NT: Androgen receptor function and androgen receptor-targeted therapies in breast cancer: A Review. JAMA Oncol 3: 1266-1273, 2017.

78. Katayama K, Yoshioka S, Tsukahara S, Mitsuhashi J and Sugimoto Y: Inhibition of the mitogen-activated protein kinase pathway results in the down-regulation of P-glycoprotein. Mol Cancer Ther 6: 2092-2102, 2007.

79. Jia Y, Zhou J, Luo X, Chen M, Chen Y, Wang J, Xiong H, Ying X, $\mathrm{Hu} \mathrm{W}$, Zhao W, et al: KLF4 overcomes tamoxifen resistance by suppressing MAPK signaling pathway and predicts good prognosis in breast cancer. Cell Signal 42: 165-175, 2017.

80. Serini S and Calviello G: Modulation of Ras/ERK and phosphoinositide signaling by long-chain n-3 PUFA in breast cancer and their potential complementary role in combination with targeted drugs. Nutrients 9: E185, 2017.

81. Wright KL, Adams JR, Liu JC, Loch AJ, Wong RG, Jo CE, Beck LA, Santhanam DR, Weiss L, Mei X, et al: Ras signaling is a key determinant for metastatic dissemination and poor survival of luminal breast cancer patients. Cancer Res 75: 4960-4972, 2015.

This work is licensed under a Creative Commons Attribution-NonCommercial-NoDerivatives 4.0 International (CC BY-NC-ND 4.0) License. 